\title{
Low versus high radioiodine activity for ablation of the thyroid remnant after thyroidectomy in Han Chinese with low-risk differentiated thyroid cancer
}

This article was published in the following Dove Press journal:

OncoTargets and Therapy

14 August 2017

Number of times this article has been viewed

\author{
Rong-Bin Lv',2 \\ Qing-Gang Wang ${ }^{2}$ \\ Chao Liu ${ }^{2}$ \\ Fang Liu ${ }^{2}$ \\ Qing Zhao ${ }^{3}$ \\ Jian-Guo Han² \\ Dao-Ling Ren ${ }^{2}$ \\ Bin Liu \\ Cheng-Li Li'
}

'Department of Interventional MRI, Shandong Medical Imaging Research Institute, Shandong University, Shandong, People's Republic of China; ${ }^{2}$ Department of Nuclear Medicine, Taian City Central Hospital, Shandong, People's Republic of China; ${ }^{3}$ Department of Interventional Radiology, Zhongshan Hospital, Fudan University, Shanghai, People's Republic of China
Correspondence: Cheng-Li Li

Department of Interventional MRI,

Shandong Medical Imaging Research

Institute affiliated to Shandong University,

Shandong Key Laboratory of Advanced

Medical Imaging Technologies and

Applications, 324 Jing wu wei jiu Road,

Huaiyin District, Jinan 25002I, Shandong,

People's Republic of China

Tel +86 I373443 3772

Email chenglilichina@yeah.net
Aim: The aim of this study was to compare the efficacy and adverse effects of radioiodine $\left.{ }^{131} \mathrm{I}\right)$ therapy between two groups of patients with low-risk differentiated thyroid cancer (DTC) who received $30 \mathrm{mCi}$ or $100 \mathrm{mCi}$ radioiodine for ablation of the thyroid remnant after total thyroidectomy.

Methods: The study cohort was 173 patients, 85 of whom were given $30 \mathrm{mCi}$ of radioiodine and the others were given $100 \mathrm{mCi}$ of radioiodine. Follow-up involved neck ultrasonography, measurement of serum levels of thyroglobulin and whole-body scans to evaluate the response of radioiodine treatment. All patients were assessed for adverse effects.

Results: Of the 173 patients, 170 (98.3\%) patients finally achieved successful ablation. The prevalence of successful ablation was $77.6 \%$ in the low-dose group versus $71.5 \%$ in the highdose group after the first dose administration $(P=0.36), 79 \%$ in the low-dose group versus $88 \%$ in the high-dose group after the second dose administration $(P=0.416)$, and $97.6 \%$ in the lowdose group versus $98.9 \%$ in the high-dose group after the final ablation $(P=0.54)$. We found no significant differences between the two groups. No patient had an adverse effect with a severity grade $>2$ and the prevalence of adverse effects in the high-dose group was higher than that in the low-dose group, especially for nausea, neck pain, and sore throat.

Conclusion: These data suggest that a low dose of radioiodine is as effective as a high dose of radioiodine for ablation of the thyroid remnant after total thyroidectomy for low-risk DTC. Moreover, low-dose radioiodine therapy is associated with a lower prevalence of adverse events.

Keywords: differentiated thyroid cancer, radioiodine, radiotherapy, thyroglobulin

\section{Introduction}

During recent few decades, thyroid cancer (TC) has been the most prevalent malignant endocrine tumor. The rise in TC incidence seems to be attributable to better detection, such as the increased use of high-resolution ultrasonography and fine-needle aspiration biopsy, which has led to enhanced detection and diagnosis of subclinical TCs. ${ }^{1}$ Approximately $90 \%$ of TCs are differentiated thyroid cancers (DTCs). That is, they arise from thyroid follicular cells and can, in general, take up iodine. This is the biologic foundation of postoperative complementary radioiodine $\left({ }^{131} \mathrm{I}\right)$ therapy. ${ }^{2}$ According to guidelines set by the Chinese Association of Nuclear Medicine, most TC patients should be treated with total or near-total thyroidectomy and then undergo adjuvant radioiodine treatment.

Postoperative complementary radioiodine therapy is effective and low-risk treatment for DTC because the long-term risk of recurrence and death is low. This beneficial effect results from the destruction of potentially malignant cells or occult 
multifocal disease that may occur in $\leq 30 \%$ of patients with papillary tumors. ${ }^{3,4}$ Furthermore, the specificity of thyroglobulin as a tumor marker is increased and the sensitivity of subsequent whole-body scans (WBSs) seems to be improved because residual thyroid tissue may compete with recurrent/ metastatic TC cells for radioiodine uptake. . $^{5-10}$

Nevertheless, the postoperative dose of radioiodine is controversial. There is a trend toward low-dose radioiodine for patients who have a good prognosis. A higher dose means higher costs - hospital admission and inconvenience to the patient, and is associated with nausea, xerophthalmia, neck pain, altered taste, and dry mouth. Therefore, recent guidelines set by the American Thyroid Association (ATA) (2015) have emphasized using the minimum effective dose of radioiodine. They state that postoperative radioiodine treatment should not be given routinely to any patient who is considered to be low-risk according to ATA guidelines. ${ }^{11}$ However, the European Association of Nuclear Medicine and the Chinese Association of Nuclear Medicine have refused to endorse the 2015 ATA management guidelines for adult patients with thyroid nodules and DTC and believe that the current strategy may not be based on robust evidence. ${ }^{12}$

We undertook a retrospective study to compare the efficacy and adverse effects of adjuvant radioiodine therapy between two groups of patients with low-risk DTC treated by total thyroidectomy and lymph-node dissection and who were then given, respectively, $30 \mathrm{mCi}$ or $100 \mathrm{mCi}$ of radioiodine for ablation of thyroid remnants.

\section{Patients and methods}

This retrospective analysis involved 173 patients treated in our department from January 2007 to January 2010. All patients met the following criteria: age $\geq 18$ years; low-risk DTC (papillary or follicular, excluding aggressive histologic subtypes) in the range of $1-4 \mathrm{~cm}$; stage pT1-T2/N0-Nx/M0 disease according to the Cancer Staging Manual (seventh edition) of the American Joint Committee on Cancer and ATA guidelines (2015); all patients underwent total thyroidectomy and lymph-node dissection if there was evidence of lymph-node involvement. We excluded patients: positive for anti-thyroglobulin antibody (TgAb); who were pregnant; with major coexisting conditions (including other cancer types) within the previous 5 years. The study was approved by the ethics committee of Taian City Central Hospital.

All participants were allocated randomly to receive lowor high-dose radioiodine. Twenty-four patients with low-risk DTC were given $100 \mathrm{mCi}$ of radioiodine in 2007, whereas 28 patients were given this dose in 2008, and 36 in 2009 .
Since 2008, this low-dose protocol was phased into our practice gradually, and $30 \mathrm{mCi}$ of radioiodine was administered to 32 patients in 2008 and to 53 patients in 2009 .

Thyroid-stimulating hormone (TSH) stimulation was achieved by abstaining from levothyroxine administration for $\geq 28$ days before radioiodine administration, with radioiodine administered when the serum concentration of thyrotropin reached $>30 \mu \mathrm{IU} / \mathrm{mL}$. A diet containing a low content of iodine was recommended before ablation. All patients underwent physical examination and biochemical evaluation before ablation of thyroid remnants. Before radioiodine administration, patients underwent an overnight fast for $\geq 9 \mathrm{~h}$ and then, after $2 \mathrm{~h}$, food was consumed. The WBS was done 3-6 days after radioiodine administration using single-photon emission computed tomography equipped with parallel-hole high-energy collimators.

Diagnostic WBS was undertaken 6-8 months after radioiodine $(5 \mathrm{mCi})$ administration. Simultaneously, we determined concentrations of TSH, stimulated thyroglobulin (STg), and TgAb in serum, and neck ultrasonography was carried out. Levels of TSH, STg, and TgAb were measured by an immunometric assay. Complete radioiodine ablation of thyroid remnants was defined by a combination of: i) normal results of neck ultrasonography; ii) undetectable ( $\leq 1 \mathrm{ng} / \mathrm{mL}$ ) serum levels of thyroglobulin; iii) absence of abnormal uptake in a diagnostic WBS. Radioiodine ablation was repeated if serum levels of thyroglobulin were detectable, if there was abnormal uptake in the thyroid bed or at extrathyroid sites in a WBS, or if there were abnormal results on neck ultrasonography. The radioactivity at repeat administration was identical to that at the first administration. Patients who underwent successful ablation were followed-up. In the first 2 years, serum levels of thyroglobulin were measured and neck ultrasonography was done every 6-8 months and WBS once a year. If there was no evidence of recurrence in the first 2 years, the follow-up cycle was prolonged to 1 year.

Adverse events related to radioiodine treatment at 1 week as well as 1 and 3 months after administration were classified according to the Common Terminology Criteria for Adverse Events v3.0 and recorded on structured forms by participants. $^{4}$

Continuous variables are presented as the mean $\pm \mathrm{SD}$ and were compared between groups by the Student's $t$-test. Categorical variables are expressed as proportions and were compared between groups with the chi-squared test or Fisher's exact test. Statistical analyses were done using SPSS v19.0 (IBM Corporation, Armonk, NY, USA). Differences were considered significant at $P<0.05$. 


\section{Ethics}

The study was approved by the ethics committee of Taian City Central Hospital. This was a retrospective study, involving no additional procedures. All procedures described herein were in accordance with the ethical standards of the institutional research committees and with the 1964 Helsinki Declaration and its later amendments or comparable ethical standards. For this type of study, formal consent is not required. However, before the radioiodine treatment described herein, written informed consent was obtained from all individual study participants. This consent included allowing use of their data in analyses such as the present study.

\section{Results \\ Patients}

Between January 2007 and January 2010, 173 patients with low-risk DTC were included in the present study. They were divided into two groups: low-dose and high-dose. Eighty-five patients received $30 \mathrm{mCi}$ of radioiodine, and the others were given $100 \mathrm{mCi}$ of radioiodine. Baseline patient characteristics are reported in Table 1. The study population comprised

Table I Patient and tumor characteristics

\begin{tabular}{|c|c|c|c|}
\hline Characteristics & $\begin{array}{l}\text { Low-dose, n (\%) } \\
(30 \mathrm{mCi}, \mathbf{N}=85)\end{array}$ & $\begin{array}{l}\text { High-dose, n (\%) } \\
(100 \text { mCi, N=88) }\end{array}$ & $P$-value \\
\hline $\begin{array}{l}\text { Age (years), } \\
\text { mean } \pm S D \text { (range) }\end{array}$ & $\begin{array}{l}45.33 \pm 14.69 \\
(19-71)\end{array}$ & $\begin{array}{l}47.89 \pm 14.82 \\
(19-75)\end{array}$ & 0.792 \\
\hline Sex & & & 0.499 \\
\hline Female & $65(76.47)$ & 71 (80.68) & \\
\hline Male & $20(23.53)$ & $17(19.32)$ & \\
\hline Histology & & & 0.775 \\
\hline Papillary & $75(88.24)$ & 80 (90.9I) & \\
\hline Follicular & $8(9.4 I)$ & 7 (7.95) & \\
\hline Follicular variant & $2(2.35)$ & I (I.14) & \\
\hline Family histology & & & 0.134 \\
\hline Yes & $3(3.53)$ & $8(9.09)$ & \\
\hline No & $82(96.47)$ & $80(90.91)$ & \\
\hline $\begin{array}{l}\mathrm{TSH}(\mu \mathrm{IU} / \mathrm{mL}) \\
\text { mean } \pm \mathrm{SD}\end{array}$ & $42.15 \pm 5.81$ & $41.83 \pm 5.63$ & 0.71 \\
\hline Tumor diameter $(\mathrm{cm})$ & $1.69 \pm 0.84$ & $1.98 \pm 0.99$ & 0.034 \\
\hline \multicolumn{2}{|c|}{ Number of lobes affected } & & 0.213 \\
\hline One & $72(84.71)$ & $68(77.27)$ & \\
\hline Both & $13(15.29)$ & $20(22.73)$ & \\
\hline Nodal metastasis & & & 0.302 \\
\hline Present & $5(5.88)$ & II (I2.5) & \\
\hline Absent & 47 (55.29) & $43(48.86)$ & \\
\hline Not rated & $33(38.82)$ & $34(38.64)$ & \\
\hline \multicolumn{2}{|l|}{ Tg level before ablation } & & 0.392 \\
\hline$<\mathrm{Ing} / \mathrm{mL}$ & $2 I(24.7 I)$ & $17(19.32)$ & \\
\hline$\geq 1 \mathrm{ng} / \mathrm{mL}$ & 64 (75.29) & 71 (80.68) & \\
\hline I31| uptake in neck (\%) & $1.50 \pm 0.86$ & $2.04 \pm 0.91$ & 0.139 \\
\hline
\end{tabular}

Abbreviations: TSH, thyroid-stimulating hormone; $\mathrm{Tg}$, thyroglobulin.
136 women and 37 men (ratio: 3.68) and the mean age was $46.63 \pm 14.77$ (range, 19-75) years. Histology showed a papillary thyroid carcinoma in $89.6 \%$ of patients, follicular thyroid carcinoma in $8.7 \%$ of patients, and a follicular variant in the rest. Apart from proportion of primary tumor diameter $(P=0.034)$, we found no significant differences in the characteristics between the two groups.

\section{Treatments, efficacy, recurrence, and adverse effects}

In total, 170 patients underwent ablation successfully (Figure 1). The prevalence of successful ablation with lowdose radioiodine was non-inferior to that with high-dose radioiodine (Table 2). The prevalence of successful ablation after first-dose administration was $74.6 \%$ overall and $77.6 \%$ in the low-dose group versus $71.5 \%$ in the high-dose group $(P=0.36)$. Then, patients in whom ablation was unsuccessful were given a second dose; the prevalence of successful ablation was $84.1 \%$ overall and $79 \%$ in the low-dose group versus $88 \%$ in the high-dose group ( $P=0.416$ ). There was no significant difference between the two groups with regard to the final successful ablation $(P=0.54)$. In addition, ablation was not successful in one patient in the high-dose group after three attempts, and so this case underwent surgery because the thyroid remnant had become too large. Ablation was not successful in two patients in the low-dose group; one of them was given high-dose radioiodine after three attempts at ablation, and ablation was finally successful; the other patient was considered to be refractory to iodine.

Radioiodine ablation was, in general, low-risk and welltolerated, and the frequency and grade of adverse effects decreased with time. During ablation and $\leq 3$ months after the procedure, no patient had an adverse effect of severity grade $>2$. Among the adverse effects related to radioiodine ablation, the prevalence of nausea, neck pain, and sore throat was significantly different between the two groups. The proportion of patients with nausea was $11.76 \%$ among the low-dose group versus $28.41 \%$ among the high-dose group $(P=0.008)$. The proportion of patients with neck pain was $16.47 \%$ among the low-dose group versus $34.09 \%$ among the high-dose group $(P=0.006)$. The proportion of patients with a sore throat was $5.88 \%$ among the low-dose group versus $15.91 \%$ among the high-dose group $(P=0.035)$. However, the prevalence of most of the other adverse effects was lower in the low-dose group, but was not significantly different between the two groups (Table 3). During follow-up, 14 patients had married and produced 18 healthy offspring, and no patient was found to have bone-marrow damage. 

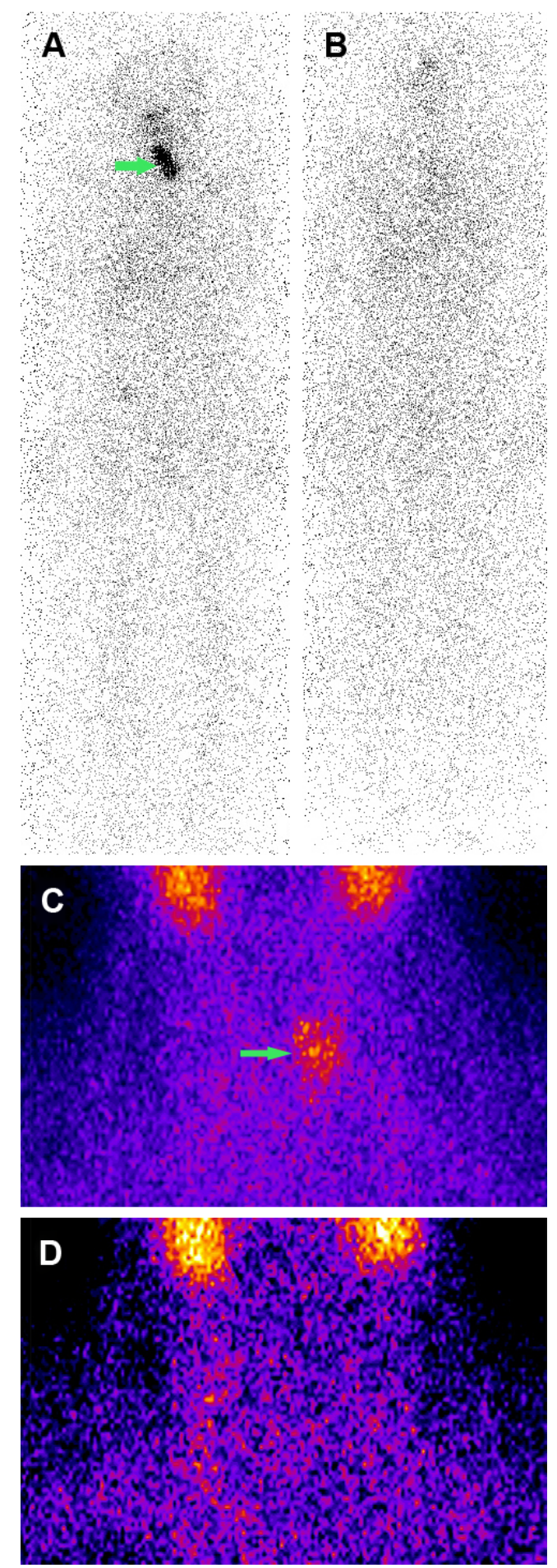

Figure I The images of WBS and thyroid static imaging of one successful ablation patient.

Notes: (A) A WBS 5 days after the procedure clearly demonstrates that after thyroidectomy the thyroid remnant has accumulated radioiodine in the neck (green arrow). (B) A WBS during follow-up shows that the accumulating spot in image $\mathbf{A}$ has been ablated by radioiodine and an abnormal accumulating spot was not found in other parts of the body. (C) Thyroid static imaging using ${ }^{99 \mathrm{~m}} \mathrm{TcO}_{4}^{-}$shows the thyroid remnant after thyroidectomy in the neck area (green arrow). (D) Thyroid static imaging using ${ }^{99 \mathrm{~m}} \mathrm{TcO}_{4}{ }^{-}$during follow-up shows no abnormal accumulating spot in the neck area. Scale for A and B: lateral axis: $170 \mathrm{~cm}$; vertical axis: $60 \mathrm{~cm}$. Scale for C and D: lateral axis: $20 \mathrm{~cm}$; vertical axis: $25 \mathrm{~cm}$.

Abbreviations: WBS, whole-body scan; ${ }^{99 \mathrm{~m}} \mathrm{TcO}_{4}^{-}$, pertechnetate.
Only one patient in the high-dose group was diagnosed with hyponatremia after radioiodine ablation on account of drinking a considerable amount of water because of fear of radiation damage. However, this hyponatremia had no direct relationship with radioiodine ablation.

We did not observe local or distant recurrence in any of the patients throughout follow-up (Table 2). No patient died from TC during follow-up, but two patients died of other reasons. One died of heart disease, and the other died in a traffic accident, neither of which were related to radioiodine ablation.

\section{Discussion}

The prognosis of DTC is good and 10-year survival can reach $>90 \%{ }^{2,13}$ Radioiodine treatment remains the cornerstone of DTC therapy combined with surgery and thyroid hormone replacement/inhibition. Radioiodine treatment can elicit many benefits: i) reduce the prevalence of recurrence and death due to DTC; ii) facilitate follow-up; iii) enable early detection of metastases..$^{14}$ Nevertheless, radioiodine treatment also carries potential risks because it can cause i) short-term discomfort in the head and neck; ii) digestivesystem disorders; iii) transient dysfunction in the salivary glands and lacrimal gland; iv) secondary tumors or fertility abnormalities. Thus, radioiodine treatment must be considered carefully before use for DTC patients, especially for patients with low-risk DTC.

Since the introduction of radioiodine in the 1940s, radioiodine treatment has been employed in doses ranging from $100 \mathrm{mCi}$ to $150 \mathrm{mCi}$ to ablate residual thyroid tissue. However, the optimal dose of radioiodine for ablation of thyroid remnants is not known. High radioactivity is most effective for the ablation of large normal-thyroid remnants and the eradication of micro-metastases; low radioactivity may be just as effective to ablate small normal-thyroid remnants after total thyroidectomy. ${ }^{15,16}$ Nevertheless, in 1976, McCowen et al reported the advantages of using a smaller dose of radioiodine $(30 \mathrm{mCi})$. They concluded that low-dose therapy $(\leq 30 \mathrm{mCi}$ ) was as effective as high-dose therapy $(80-100 \mathrm{mCi})$ in their patient cohort. ${ }^{17}$ After that provocative report, in the late 1970 s, low-dose radioiodine ablation of thyroid remnants was introduced and, subsequently, many centers confirmed the effectiveness of such therapy. However, in some studies, the success rate was greater with higher doses. Siddiqui et al reported that a high dose (100-150 mCi) was a more conventional dose and a low dose $(30 \mathrm{mCi})$ could not be used to ablate thyroid remnants using the clinical 
Table 2 Success and recurrence of ablation of the thyroid remnant using radioiodine

\begin{tabular}{|c|c|c|c|c|c|c|c|}
\hline \multirow[t]{2}{*}{ Study groups } & \multicolumn{2}{|c|}{ First-ablation outcome } & \multicolumn{2}{|c|}{ Second-ablation outcome } & \multicolumn{2}{|c|}{ Final-ablation outcome } & \multirow[t]{2}{*}{ Recurrence } \\
\hline & Success & Failure & Success & Failure & Success & Failure & \\
\hline Low-dose, n (\%) & 66 & 19 & 15 & $4(2 \mid \%)$ & 83 & $2(2.4 \%)$ & 0 \\
\hline$(30 \mathrm{mCi}, \mathrm{N}=85)$ & (77.6\%) & $(22.4 \%)$ & $(79 \%)$ & & $(97.6 \%)$ & & \\
\hline High-dose, n (\%) & 63 & 25 & 22 & $3(22 \%)$ & 87 & I (I.I\%) & 0 \\
\hline$(100 \mathrm{mCi}, \mathrm{N}=88)$ & (71.5\%) & $(28.5 \%)$ & $(88 \%)$ & & $(98.9 \%)$ & & \\
\hline$P$-value & 0.36 & & 0.416 & & 0.54 & & \\
\hline \multirow[t]{2}{*}{ Total } & $129 / 173$ & & $37 / 44$ & & $170 / 173$ & & 0 \\
\hline & (74.6\%) & & $(84.1 \%)$ & & $(98.3 \%)$ & & \\
\hline
\end{tabular}

protocols stated by McCowen et al. ${ }^{18}$ Doi and Woodhouse supported those findings and reported that doses $<75 \mathrm{mCi}$ were less effective than $100 \mathrm{mCi} .{ }^{19}$ Interestingly, Kukulska et al showed that $30 \mathrm{mCi}$ of radioiodine was less effective than $60 \mathrm{mCi}$ of radioiodine and that $60 \mathrm{mCi}$ of radioiodine was as effective as $100 \mathrm{mCi}$ of radioiodine..$^{20}$

Table 3 Common adverse effects related to radioiodine ablation

\begin{tabular}{|c|c|c|c|}
\hline Adverse effects & $\begin{array}{l}\text { Low-dose, } \mathbf{N}(\%) \\
(30 \mathrm{mCi}, \mathbf{N}=85)\end{array}$ & $\begin{array}{l}\text { High-dose, } \mathbf{N}(\%) \\
(100 \mathrm{mCi}, \mathrm{N}=88)\end{array}$ & $P$-value \\
\hline \multicolumn{4}{|l|}{ Nausea } \\
\hline I week & $10(11.76)$ & $25(28.4 I)$ & 0.006 \\
\hline I month & $2(2.35)$ & 8 (9.09) & 0.058 \\
\hline 3 months & I (I.I8) & $3(3.4 I)$ & 0.329 \\
\hline \multicolumn{4}{|l|}{ Neck pain } \\
\hline I week & 14 (16.47) & 30 (34.09) & 0.008 \\
\hline I month & $10(11.76)$ & $13(14.77)$ & 0.56 \\
\hline 3 months & $5(5.88)$ & $9(10.23)$ & 0.295 \\
\hline \multicolumn{4}{|l|}{ Radiation gastritis } \\
\hline I week & $2(2.35)$ & $4(4.55)$ & 0.431 \\
\hline I month & I (I.18) & I (I.I4) & 0.98 \\
\hline 3 months & $0(0)$ & $0(0)$ & \\
\hline \multicolumn{4}{|l|}{ Radiation cystitis } \\
\hline I week & I (I.I8) & $2(2.27)$ & $0.58 \mathrm{I}$ \\
\hline I month & $0(0)$ & $0(0)$ & \\
\hline 3 months & $0(0)$ & $0(0)$ & \\
\hline \multicolumn{4}{|l|}{ Taste dysfunction } \\
\hline I week & $7(8.24)$ & II (I2.5) & 0.358 \\
\hline I month & $4(4.7 I)$ & $7(7.95)$ & 0.381 \\
\hline 3 months & I (I.I8) & $2(2.27)$ & $0.58 \mathrm{I}$ \\
\hline \multicolumn{4}{|l|}{ Salivary dysfunction } \\
\hline I week & $6(7.06)$ & $10(11.36)$ & 0.329 \\
\hline I month & $3(3.53)$ & $4(4.55)$ & 0.735 \\
\hline 3 months & I (I.I8) & I (I.I4) & 0.98 \\
\hline \multicolumn{4}{|l|}{ Sore throat } \\
\hline I week & $5(5.88)$ & 14 (I5.9I) & 0.035 \\
\hline I month & $2(2.35)$ & $7(7.95)$ & 0.097 \\
\hline 3 months & $0(0)$ & $0(0)$ & \\
\hline \multicolumn{4}{|l|}{ Dry eyes } \\
\hline I week & $6(7.06)$ & $9(10.23)$ & 0.459 \\
\hline I month & $5(5.88)$ & $4(4.55)$ & 0.692 \\
\hline 3 months & $3(3.53)$ & $3(3.4 I)$ & 0.966 \\
\hline Serious adverse events & $0(0)$ & I $(1.14)^{*}$ & \\
\hline
\end{tabular}

Note: *Hyponatremia.
Recently, in a multicenter, randomized non-inferiority study conducted by Mallick et al, 438 patients with DTC were randomized to receive low-dose $(30 \mathrm{mCi})$ radioiodine and high-dose $(100 \mathrm{mCi})$ radioiodine. The success of ablation was $85.0 \%$ in the low-dose group versus $88.9 \%$ in the high-dose group. In a randomized Phase III study conducted by Schlumberger et al, 752 patients with low-risk DTC were randomized to receive low-dose $(30 \mathrm{mCi})$ radioiodine and high-dose $(100 \mathrm{mCi})$ radioiodine, and the success of ablation between the two groups was found to be equivalent. ${ }^{3,4}$ Those two studies had important methodological advantages not only in sample size, but also in prospective randomized design. Also, they reported clearly better success rates (85\%-94\%) and they compared differences in preparation by means of recombinant human thyrotropin or withholding of thyroid hormone, and equivalent results were achieved. Four randomized studies comparing therapeutic doses of $30 \mathrm{mCi}$ and $100 \mathrm{mCi}$ showed that $30 \mathrm{mCi}$ was equivalent to that of $100 \mathrm{mCi}^{21-24}$

We retrospectively analyzed the outcomes of 173 Han Chinese patients with low-risk DTC treated by radioiodine after total thyroidectomy. We wanted to know if different ethnicities, lifestyles, and dietary habits could affect study results. We found no conclusive evidence that the high-dose $(100 \mathrm{mCi})$ radioiodine was more effective than low-dose $(30 \mathrm{mCi})$ radioiodine. The success rate in our study was $77.6 \%$ in the low-dose group versus $71.5 \%$ in the high-dose group after the first course of treatment and, finally, was $97.6 \%$ in the low-dose group versus $98.9 \%$ in the high-dose group. Previously reported success rates for radioiodine ablation after thyroidectomy using low or high radioiodine doses have been 10\%-98\%. In our opinion, the different success rates for radioiodine ablation are due mainly to variations in the extent of surgery and inconsistent definitions of "successful ablation". In our study, successful ablation was confirmed by normal findings of neck ultrasonography, undetectable serum levels 
of thyroglobulin, and an absence of abnormal uptake in a diagnostic WBS.

Notably, in our study, the severity of all adverse effects associated with radioiodine treatment was mild (grade 1 or 2), and most of the adverse effects between the two groups were not different except for nausea, neck pain, and sore throat 1 week after the procedure. All patients could tolerate symptomatic treatment and there were no unexpected serious adverse events. Mild adverse effects associated with radioiodine treatment have also been noted by other researchers. ${ }^{3,4,22}$ They reported that radioiodine treatment was, in general, well-tolerated and that lower radioactivity was associated with less nausea, taste disturbances, and pain in the salivary glands. After follow-up for $>5$ years, we did not find that radioiodine treatment (even if carried out more than once) resulted in secondary tumors, fertility abnormalities, or other serious adverse effects. This finding is despite the fact that, according to recent ATA guidelines, radioiodine treatment is used only for more advanced DTC stages in the USA. ${ }^{11}$ In our opinion, radioiodine treatment should be used for low-risk DTC because it allows elimination of postoperative remnants and better follow-up through improvement in the measurement specificity of serum levels of thyroglobulin and sensitivity of the WBS; moreover, it is safe for patients.

During follow-up, we did not find recurrence in either group, so current treatments for low-risk DTC were effective. However, one patient in the low-dose group was considered to be refractory to iodine after three treatments. Our study cohort was small, so we could not verify the theory advanced by Wartofsky et al: during radioiodine treatment, if the first dose does not kill TC cells but just damages them, then cells will no longer absorb radioiodine, and the patient will become refractory to iodine. ${ }^{25} \mathrm{~A}$ larger study cohort, multicenter setting, and long-term follow-up studies are needed to confirm our findings.

A potential limitation of our study was that short-term follow-up was not sufficient to investigate more important endpoints (survival, the prevalence of local relapse, distant metastases, and recurrence) or to evaluate the long-term adverse events of the radioiodine treatment. Other limitations included the retrospective design of our study and the small number of patients.

\section{Conclusion}

The present study showed a similar prevalence of thyroidremnant ablation among Han Chinese participants with low-risk DTC after total thyroidectomy when $30 \mathrm{mCi}$ or $100 \mathrm{mCi}$ radioiodine was used. Moreover, low-dose radioiodine therapy was associated with a lower prevalence of adverse effects. Thus, use of a low dose of radioiodine for postoperative radioiodine ablation could be an effective and attractive option for the treatment of low-risk DTC because it reduces the prevalence of adverse effects and maintains a good quality of life.

\section{Acknowledgments}

The authors thank the nursing staff of the Department of Nuclear Medicine of Taian City Central Hospital, for skillful assistance. We thank Su Jun, PhD, for help in the statistical analysis of the data. The first author had full access to all of the data in the study and takes responsibility for the integrity of the data and the accuracy of the data analysis. This was an investigator-initiated study funded from the regular budgets of the Department of Nuclear Medicine of Taian City Central Hospital.

\section{Disclosure}

The authors report no conflicts of interest in this work.

\section{References}

1. Kitahara CM, Sosa JA. The changing incidence of thyroid cancer. Nat Rev Endocrinol. 2016;12(11):646-653.

2. Sipos JA, Mazzaferri EL. Thyroid cancer epidemiology and prognostic variables. Clin Oncol (R Coll Radiol). 2010;22(6):395-404.

3. Schlumberger M, Catargi B, Borget I, et al. Strategies of radioiodine ablation in patients with low-risk thyroid cancer. N Engl J Med. 2012; 366(18):1663-1673.

4. Mallick U, Harmer C, Yap B, et al. Ablation with low-dose radioiodine and thyrotropin alfa in thyroid cancer. N Engl J Med. 2012;366(18): 1674-1685.

5. Han JM, Kim WG, Kim TY, et al. Effects of low-dose and high-dose postoperative radioiodine therapy on the clinical outcome in patients with small differentiated thyroid cancer having microscopic extrathyroidal extension. Thyroid. 2014(5);24:820-825.

6. Song X, Meng Z, Jia Q, et al. Different radioiodine dose for remnant thyroid ablation in patients with differentiated thyroid cancer: a metaanalysis. Clin Nucl Med. 2015;40(10):774-779.

7. Ceccarelli C, Bencivelli W, Morciano D, Pinchera A, Pacini F. ${ }^{131}$ I therapy for differentiated thyroid cancer leads to an earlier onset of menopause: results of a retrospective study. J Clin Endocrinol Metab. 2001;86(8):3512-3515.

8. Tsang RW, Brierley JD, Simpson WJ, Panzarella T, Gospodarowicz MK, Sutcliffe SB. The effects of surgery, radioiodine, and external radiation therapy on the clinical outcome of patients with differentiated thyroid carcinoma. Cancer. 1998;82(2):375-388.

9. Mazzaferri EL, Kloos RT. Clinical review 128: current approaches to primary therapy for papillary and follicular thyroid cancer. J Clin Endocrinol Metab. 2001;86(4):1447-1463.

10. Sawka AM, Brierley JD, Tsang RW, et al. An updated systematic review and commentary examining the effectiveness of radioactive iodine remnant ablation in well-differentiated thyroid cancer. Endocrinol Metab Clin North Am. 2008;37(2):457-480.

11. Haugen BR, Alexander EK, Bible KC, et al. 2015 American Thyroid Association management guidelines for adult patients with thyroid nodules and differentiated thyroid cancer: the American Thyroid Association Guidelines Task Force on thyroid nodules and differentiated thyroid cancer. Thyroid. 2016;26(1):1-133. 
12. Verburg FA, Aktolun C, Chiti A, et al. Why the European Association of Nuclear Medicine has declined to endorse the 2015 American Thyroid Association management guidelines for adult patients with thyroid nodules and differentiated thyroid cancer. Eur J Nucl Med Mol Imaging. 2016;43(6):1001-1005.

13. Qu Y, Huang R, Li L. Low- and high-dose radioiodine therapy for low-/intermediate-risk differentiated thyroid cancer: a preliminary clinical trial. Ann Nucl Med. 2016;31(1):71-83.

14. Pacini F, Schlumberger M, Dralle H, Elisei R, Smit JW, Wiersinga W; European Thyroid Cancer Taskforce. European consensus for the management of patients with differentiated thyroid carcinoma of the follicular epithelium. Eur J Endocrinol. 2006;154(6):787-803.

15. Sawka AM, Thephamongkhol K, Brouwers M, Thabane L, Browman G, Gerstein HC. Clinical review 170: a systematic review and meta analysis of the effectiveness of radioactive iodine remnant ablation for well-differentiated thyroid cancer. J Clin Endocrinol Metab. 2004; 89(8):3668-3676.

16. Hackshaw A, Harmer C, Mallick U, Haq M, Franklyn JA. ${ }^{131}$ I activity for remnant ablation in patients with differentiated thyroid cancer: a systematic review. J Clin Endocrinol Metab. 2007;92(1):28-38.

17. McCowen KD, Adler RA, Ghaed N, Verdon T, Hofeldt FD. Low dose radioiodide thyroid ablation in postsurgical patients with thyroid cancer. Am J Med. 1976;61(1):52-58.

18. Siddiqui AR, Edmondson J, Wellman HN, et al. Feasibility of low doses of ${ }^{131} \mathrm{I}$ for thyroid ablation in postsurgical patients with thyroid carcinoma. Clin Nucl Med. 1981;6(4):158-161.
19. Doi SA, Woodhouse NJ. Ablation of the thyroid remnant and ${ }^{131}$ I dose in differentiated thyroid cancer. Clin Endocrinol (Oxf). 2000;52(6): 765-773.

20. Kukulska A, Krajewska J, Gawkowska-Suwinska M, et al. Radioiodine thyroid remnant ablation in patients with differentiated thyroid carcinoma (DTC): prospective comparison of long-term outcomes of treatment with 30, 60 and $100 \mathrm{mCi}$. Thyroid Res. 2010;3(1):9.

21. Maenpaa HO, Heikkonen J, Vaalavirta L, Tenhunen M, Joensuu H. Low vs. high radioiodine activity to ablate the thyroid after thyroidectomy for cancer: a randomized study. PLoS One. 2008;3(4):e1885.

22. Johansen K, Woodhouse NJ, Odugbesan O. Comparison of 1073 and $3700 \mathrm{MBq}$ iodine-131 in postoperative ablation of residual thyroid tissue in patients with differentiated thyroid cancer. J Nucl Med. 1991; 32(2):252-254.

23. Taube A, Lundell G. Prospective randomized clinical trial to evaluate the optimal dose of ${ }^{131}$ I for remnant ablation in patients with differentiated thyroid carcinoma. Cancer. 1997;79(1):190-191.

24. Fallahi B, Beiki D, Takavar A, et al. Low versus high radioiodine dose in postoperative ablation of residual thyroid tissue in patients with differentiated thyroid carcinoma: a large randomized clinical trial. Nucl Med Commun. 2012;33(3):275-282.

25. Wartofsky L, Van Nostrand D. Radioiodine treatment of well-differentiated thyroid cancer. Endocrine. 2012;42(3):506-513.
OncoTargets and Therapy

\section{Publish your work in this journal}

OncoTargets and Therapy is an international, peer-reviewed, open access journal focusing on the pathological basis of all cancers, potential targets for therapy and treatment protocols employed to improve the management of cancer patients. The journal also focuses on the impact of management programs and new therapeutic agents and protocols on

\section{Dovepress}

patient perspectives such as quality of life, adherence and satisfaction. The manuscript management system is completely online and includes a very quick and fair peer-review system, which is all easy to use. Visit http://www.dovepress.com/testimonials.php to read real quotes from published authors. 